Errata

\title{
Effects of gestational diabetes on human placental glucose uptake, transfer, and utilisation
}

\author{
D.T.D. Osmond ${ }^{1}$, C.J.Nolan ${ }^{2}$, R. G. King ${ }^{3}$, S.P. Brennecke ${ }^{4}$, N. M. Gude ${ }^{1}$ \\ ${ }^{1}$ Department of Perinatal Medicine, Royal Women's Hospital, Carlton Victoria, Australia \\ ${ }^{2}$ Department of Obstetrics and Gynaecology, University of Melbourne, Royal Women's Hospital, Carlton Victoria, Australia \\ ${ }^{3}$ Department of Pharmacology, Monash University, Clayton Victoria, Australia \\ ${ }^{4}$ Consultant Endocrinologist, Geelong Hospital, Geelong Victoria, Australia
}

Diabetologia (2000) 43: 576-582

The legend at the top of Table 1 on page 578 should read:

"Table 1. Characteristics of pregnant GDM and control subjects whose placentae were studied, presented as means \pm SEM."

\section{Heterogeneity of Type I diabetes: analysis of monozygotic twins in Great Britain and the United States}

\author{
M.J.Redondo ${ }^{1}$, L. Yu ${ }^{1}$, M.Hawa ${ }^{2}$, T.Mackenzie ${ }^{3}$, D.A.Pyke ${ }^{2 \dagger}$, G.S. Eisenbarth ${ }^{1}$, R.D. G. Leslie ${ }^{2}$ \\ ${ }^{1}$ Barbara Davis Center for Childhood Diabetes, University of Colorado Health Sciences Center, Denver, Colorado, USA \\ ${ }^{2}$ Department of Diabetes and Metabolism, St. Bartholomew's Hospital, London, UK \\ ${ }^{3}$ Department of Preventive Medicine and Biometrics, University of Colorado Health Sciences Center, Denver, Colorado, USA
}

Diabetologia (2001) 44: 354-362

Acknowledgements: This study was supported by the National Institutes of Health Grants DK 32083-16, the American Diabetes Foundation and the Children's Diabetes Foundation. M.J.Redondo was supported by the Fondo de Investigacion Sanitaria (F. I. S. 98/9211). We thank T. Smith, research nurse, who has for more than three decades implemented twin studies, A. Corcoran and P. Sawtell, research coordinators, and Medical Research Council, Wellcome Trust, British Diabetic Association, St. Bartholomews Joint Research Board, British Diabetic Twin Trust. We thank our many research fellows and the twins themselves for their cooperation. 